\title{
SERVIÇO DE PROTEÇÃO E ATENDIMENTO ESPECIALIZADO A FAMÍLIAS E INDIVÍDUOS (PAEFI) DE FLORIANÓPOLIS: UM LEVANTAMENTO RACIAL
}

\author{
Gisely Pereira Botega ${ }^{1}$ \\ Pamela Cristina dos Santos ${ }^{2}$
}

\begin{abstract}
Resumo
Este artigo teve como principal objetivo refletir sobre a produção de dados estatísticos referentes ao quesito raça/cor, do ano de 2016, realizados por psicólogos(as) e assistentes sociais de um serviço de Proteção e Atendimento Especializado a Famílias e Indivíduos (PAEFI) situado dentro do Centro de Referência de Assistência Social (CREAS) localizado na Grande Florianópolis. Assim, mapeamos as marcações de raça/cor através estatísticas produzidas mensalmente pelos(as) profissionais deste serviço, os(as) quais priorizavam uma abordagem de trabalho psicossocial frente aos direitos violados de crianças, adolescentes e suas famílias. Os resultados apontam para uma ausência desta marcação quantitativa nas estatísticas sugerindo um processo de invisibilidade diante das questões raciais que podem produzir violências em diferentes contextos.
\end{abstract}

Palavras-chave: Raça/cor. Serviço PAEFI. Violência racial. Crianças e adolescentes.

1 Doutora e mestre em Educação pela Universidade Federal de Santa Catarina (UFSC). Psicóloga do serviço de Proteção e Atendimento Especializado a Famílias e Indivíduos (PAEFI) do Centro de Referência de Assistência Social (CREAS/ILHA). Professora do curso de Psicologia da UNISUL e integrante do Centro de Ciências da Educação (CED) Núcleo Vida e Cuidado (NUVIC) da UFSC. E-mail: gibotega@gmail.com.

2 Mestre em Educação pela Universidade Federal de Santa Catarina (UFSC). Professora da Rede Básica de Ensino do Serviço Social do Comércio (SESC/SC). Integrante do Grupo de Pesquisa Alteritas: Diferença, Arte e Educação e do Núcleo Vida e Cuidado (NUVIC) Centro de Ciências da Educação (CED) da UFSC. E-mail: s.pamelacristina@gmail.com 


\section{Apresentação}

Este texto teve como objetivo principal analisar dados estatísticos produzidos no ano de 2016 pelo Serviço de Proteção e Atendimento a Famílias e Indivíduos (PAEFI) situado dentro do Centro Especializado de Assistência Social (CREAS) do município de Florianópolis (SC). Buscamos analisar como o quesito raça/cor apareceu nestes dados voltados a crianças, adolescentes e suas famílias em situações e contextos de violências, vulnerabilidade social e quais relações são possíveis de tecer com os desdobramentos psicossociais da violência racial.

A aproximação com o serviço PAEFI-ILHA ocorreu através do projeto de extensão desenvolvido pelo Núcleo Vida e Cuidado (NUVIC): estudos e pesquisas sobre violências do Centro de Ciências da Educação (CED) da Universidade Federal de Santa Catarina (UFSC), intitulado como: "Rede de Proteção, Defesa e Controle Dos Direitos: mapeamento do risco e da vulnerabilidade na infância em Florianópolis"3. Tal projeto relacionavase às políticas de Atenção à Infância deflagrada por meio da Lei Federal no 8.069, de 13 de julho 1990 - Estatuto da Criança e do Adolescente (ECA) -, com o mapeamento da rede de proteção, defesa e controle dos direitos das crianças e dos adolescentes, e tinha como principal objetivo mapear as situações de risco e vulnerabilidade da Infância em Florianópolis.

Os dados estatísticos utilizados neste trabalho foram retirados das planilhas produzidas mensalmente por cada técnico(a) do Serviço PAEFI (psicólogos(as) e assistentes sociais). A partir desse primeiro contato com os dados, realizamos um compilamento destes cruzando as informações registradas sobre as famílias com as violências. Para tanto, utilizamos o banco de dados do Centro de referência Especializado em Assistência Social (CREAS), mais especificamente, no Programa de Atendimento a Famílias e Indivíduos (PAEFI). Do primeiro contato com os dados até a estruturação de uma planilha de coletas, temos uma distância temporal de dois meses. Paralelamente a isso, a cada 15 dias, durante toda a inserção no PAEFI, foram realizadas reuniões de estudo que auxiliaram no processo de problematização e ampliação do nosso olhar diante os dados estatísticos.

Após a coleta dos dados do primeiro semestre de 2016, ensaiamos uma análise a partir da confecção de gráficos, já que toda esta produção esteve atrelada à matriz teórica e metodológica do NUVIC acerca das violências ${ }^{4}$. Os dados produzidos e analisados por nós permitiram um breve mapeamento das violências que acometem as crianças e os adolescentes, e nesse daremos destaque à violência racial.

Considerando que este estudo atingiu uma demanda pontual de análises de documentos acessados através do Serviço PAEFI, assumimos para essa pesquisa um caráter quantitativo e qualitativo. De acordo com Gil
3 O referido projeto foi coordenado pela Professora Doutora Patrícia de Moraes Lima vinculada à linha de Educação e Infância (CED/UFSC) e coordenadora do NUVIC. Tal projeto contou com a participação de estudantes de Pedagogia e uma profissional de Psicologia do PAEFI-ILHA.

4 Tais como: Arendt (2009); Lima (2015, 2016); Sousa (2002, 2006, 2011); Souza, Lima e Miguel (2010), entre outras. 
5 SCIELO é uma base eletrônica de bibliografias produzidas por periódicos científicos brasileiros de diversas áreas do conhecimento e PePSIC "é uma fonte da Biblioteca Virtual em Saúde - Psicologia da União Latino-Americana de Entidades de Psicologia (BVS-Psi ULAPSI)".
(2002, p. 62-63), tal pesquisa trata-se de materiais autênticos caracterizandose como uma fonte "rica de dados, o que também estamos compreendo como maneiras de explorar que não podem ser exclusivamente contabilizados devido as especificidades das realidades sociais que acompanham.

Com o intuito de traçar um breve panorama das publicações sobre a temática pesquisada neste trabalho, elaboramos uma revisão das produções acadêmicas com base nos resumos de artigos em duas bases de dados: Scientific Eletronic Library Online (SCIELO) e Periódicos Eletrônicos em Psicologia (PePSIC) $)^{5}$ sem recorte temporal. Utilizamos quatro descritores: PAEFI e violência Racial; CREAS e violência racial; PAEFI; CREAS. Nos três primeiros descritores, não encontramos nenhum artigo. Somente com o descritor CREAS, foi encontrado um total de 22 artigos nas duas bases de dados, sendo 11 na base de dados SCIELO e 11 na base de dados PePSIC. Após a leitura dos resumos, observamos que nenhum deles fez referência ao tema da violência racial ou ao quesito raça/cor. De modo geral, as publicações começaram a partir do ano de 2011, intensificando-se a partir de 2014 e concentraram-se em quatro eixos temáticos: abuso sexual infantil, violência doméstica, adolescentes e vulnerabilidade social e atuação profissional no CREAS.

Das leituras realizadas, queremos dar destaque ao trabalho de Lima e Schneider (2018) sobre a atuação dos(as) psicólogos(as) na proteção social especial em Santa Catarina a qual identificou que existiam 464 psicólogos(as) cadastrados(as) nos 83 municípios que possuem CREAS em Santa Catarina. Sabe-se que, além dos(as) psicólogos(as), o CREAS possui também profissionais da assistência social, advogados(as) e auxiliares administrativos(as) em suas equipes de referências conforme preconiza a Tipificação Nacional de Serviços Socioassistenciais (BRASIL, 2009). Estas informações sobre as equipes de referências dos CREAS em Santa Catarina atrelada ao fato de não encontrarmos nenhum artigo que fazia menção à violência racial, bem como ao fato de as publicações serem bem recentes, nos possibilitam apontar sobre a relevância social e científica de nossa pesquisa no sentido de afirmar nosso compromisso ético e político diante da categoria raça/cor nas políticas públicas voltadas a crianças e adolescentes em contextos de violação de direitos.

\section{Antes do PAEFI/Ilha: historicidade das políticas redes de proteção às crianças e aos adolescentes em Florianópolis}

O Serviço de Proteção e Atendimento Especializado a Famílias e Indivíduos é uma política pública prevista na Tipificação Nacional de Serviços Socioassistenciais (BRASIL, 2009) que funciona exclusivamente no CREAS. No município de Florianópolis, o CREAS/Ilha fica localizado na região central da ilha, no bairro agronômica. Atualmente, além do 
CREAS/Ilha, existe um CREAS que atende à região continental de Florianópolis. As equipes de referências são compostas por profissionais de Psicologia, Assistência Social, Pedagogia, Auxílio Administrativo e Motoristas. Até a publicação deste trabalho, não existiam profissionais advogados(as) nas equipes de referências dos dois CREAS do município.

Figura 1 - Imagem de Satélite do CREAS/Ilha

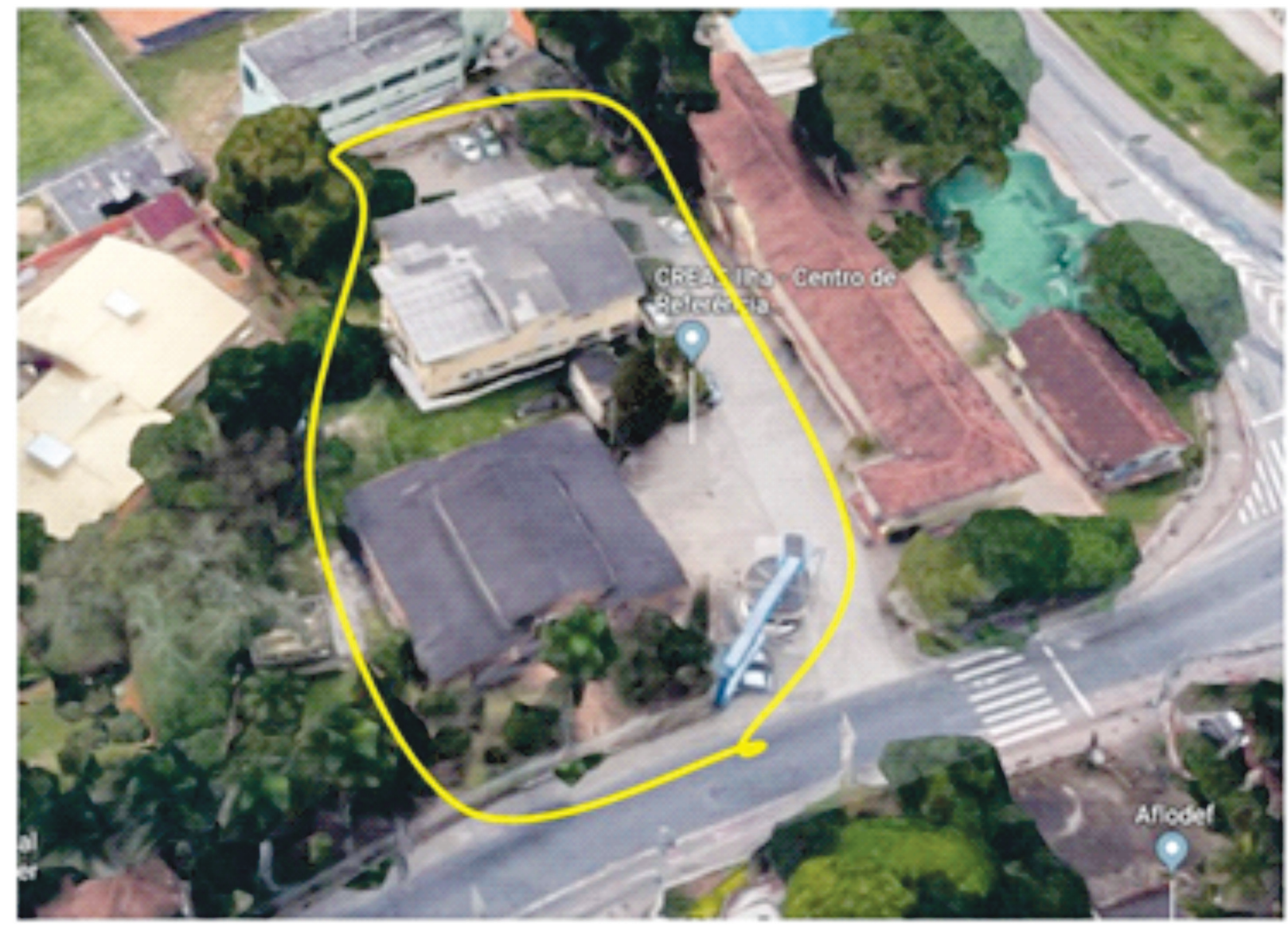

Fonte: Google Maps (2019). Localização PAEFI/Ilha.

O espaço arquitetônico do serviço PAEFI/ILHA é marcado pela historicidade que a política pública anterior deixou. Vale destacar que os cuidados relativos à proteção de crianças e adolescentes em Florianópolis datam dos anos de 1991, com a fundação do projeto SOS Criança. Este projeto tinha por objetivo atender a crianças e adolescentes cujos direitos, assegurados pelo ECA, estivessem de alguma forma ameaçados. As denúncias eram feitas através de central telefônica e/ou na sede do projeto. Os atendimentos, por sua vez, eram emergenciais; assim, não existia acompanhamento posterior às vítimas (SILVA, 2004). A partir de 1993, momento em que o ECA começou a se consolidar, os atendimentos do SOS criança foram municipalizados e, em 1999, este já se torna responsabilidade exclusiva do município de Florianópolis. 
6 A Norma Operacional Básica 2005 disciplina a operacionalização da gestão da política de assistência social, conforme a Constituição Federal de 1988, a LOAS e legislação complementar aplicável nos termos da Política Nacional de Assistência Social de 2004, sob a égide de construção do SUAS, abordando, dentre outras coisas: a divisão de competências e responsabilidades entre as três esferas de governo; os níveis de gestão de cada uma dessas esferas; as instâncias que compõem o processo do qual se relacionam; a nova relação com as entidades e organizações governamentais e não governamentais; os principais instrumentos de gestão a serem utilizados; e a forma da gestão financeira, que considera os mecanismos de transferência, os critérios de partilha e de transferência de recursos (BRASIL, 2005, p. 12).
Adentrando nos anos 2000 o Governo Federal, com a consolidação do Plano Nacional de Enfrentamento da Violência Sexual Infanto-Juvenil, o Programa Sentinela chegou a Florianópolis. Por já existirem projetos que tratavam dos direitos das crianças e dos adolescentes no município, o programa se dividiu em três projetos a fim de contemplar as três linhas de ações, definidas pela Portaria no 878, de 3 de dezembro de 2001, são elas: diagnóstico, atendimento psicossocial e prevenção. Nesse sentido, a estrutura de atendimento às crianças vítimas de violências ficou organizada da seguinte forma:

I. Projeto Mel: Responsável pela prevenção das situações de risco envolvendo crianças e adolescentes com a realização de palestras, oficinas e cursos.

II. SOS criança (nomenclatura utilizada até o ano de 2004, posteriormente substituída por Projeto Primeiro Atendimento): as atribuições deste projeto pautavam-se no atendimento inicial das vítimas e no diagnóstico das violências. Feito isto, ficava sob responsabilidade do projeto conduzir o relatório Situacional ao Conselho Tutelar.

III. Projeto Acorde: encarregava-se dos atendimentos de crianças e adolescentes cujo diagnóstico de violências era classificado como grave.

A partir de 2005, com a Norma Operacional Básica (NOB) do Sistema Único de Assistência Social (SUAS) ${ }^{6}$, o Programa Sentinela sofreu alterações no que diz respeito ao modo de funcionamento, e os atendimentos foram categorizados por três equipes de atendimento: Diagnóstico, Acompanhamento e de Trabalho em Rede. Organizando-se da seguinte maneira:

I. Equipe de Trabalho em Rede: trabalhava na prevenção das violências atuando com crianças, adolescentes e suas respectivas famílias através de intervenções nas escolas. Segundo o Projeto Técnico de Florianópolis (2005, p.5): “O objetivo geral se referia à implementação da articulação das ações do poder público e da sociedade civil visando a assegurar a prevenção da violência doméstica contra crianças e adolescentes nos níveis primário, secundário e terciário".

II. Equipe de Diagnóstico: Tinha por objeto principal “[...] realizar diagnóstico psicossocial dos casos de violência doméstica contra crianças e adolescentes avaliando os fatores de risco e proteção (Florianópolis, 2005, p. 4)”. A equipe de diagnóstico recebia as denúncias vindas do Conselho Tutelar para, então, iniciar um primeiro estudo sobre a situação de violência vivenciada pela criança e/ou pelo adolescente, emitindo um parecer social da situação e encaminhado o caso para órgãos responsáveis como delegacias, Conselhos Tutelares e/ou judiciário (Alencar, 2007). 
III. Equipe de Acompanhamento: tinha por objetivo geral “[...] a implantação de acompanhamento sistemático e articulado por meio de encontros grupais com crianças, adolescentes e suas famílias (Florianópolis, 2005, p. 5)". A equipe de acompanhamento trabalhava com crianças e/ou adolescentes que se encontravam em situações possíveis de risco; após o atendimento, era emitido um relatório para a equipe de diagnóstico.

O atendimento no Programa Sentinela, a partir de 2005, começou a ganhar estrutura de atendimento em rede, atendendo a crianças e adolescentes não só em caráter emergencial mas também compondo uma trama sequencial de atendimento que possibilitava à criança ou ao adolescente subsídios para lidar com as amarras geradas pela violência sofrida. $\mathrm{O}$ atendimento das crianças em rede pelas políticas públicas veio se modificando ao longo dos anos, sendo caracterizado hoje como um conjunto de "[...] ações entre indivíduos e organizações que se tecem ou se dissolvem em todos os campos da vida societária (ZAPELINI, 2010, p. 129)" e que, a partir disso, vem pautando a necessidade de participação de todos os sujeitos que compõem as políticas como atores sociais.

Assim, o espaço físico que abrigou o SOS criança, Programa Sentinela e que hoje abriga o CREAS/PAEFI é um também espaço simbólico e de referência no município destinado à proteção de crianças e adolescentes que vivenciam violências. O CREAS é um programa vinculado ao Sistema Único de Assistência Social (SUAS), sendo este um dever do Estado para com cidadãos e cidadãs, e funciona em conjunto com a sociedade privada. Caracteriza-se por ser uma política social não contributiva que visa à seguridade social em trabalho conjunto com a Saúde e a Previdência Social. A partir de 2005, o SUAS foi considerado: “[...] descentralizado e participativo, que tem por função a gestão do conteúdo específico da Assistência Social no campo da proteção social brasileira" (Governo do Estado de São Paulo, 2016); e, em 2011, foi formatado para atuar em dois níveis de complexidade: Proteção Social Básica e Proteção Social Especial.

A Proteção Social Básica é a porta de entrada do SUAS, caracteriza-se por prestar serviços de prevenção de famílias em "situação de vulnerabilidade e risco social” (PEGASO, [s. d.]). através de programas e benefícios disponibilizados pelo Governo Federal, e o principal órgão responsável por viabilizar estes processos é o Centro de Referência em Assistência Social (CRAS). Já Proteção Social Especial é destinada a famílias e indivíduos cujos direitos foram violados; assim, trabalha-se para fortalecer os vínculos familiares, comunitários e sociais e para ampliar a função protetiva da família. Dentro do CREAS existem programas específicos para tratar dos indivíduos com suspeitas ou confirmação de direitos violados, como podemos observar no esquema a seguir: 
Figura 2 - Organograma da estrutura da Política de Assistência Social

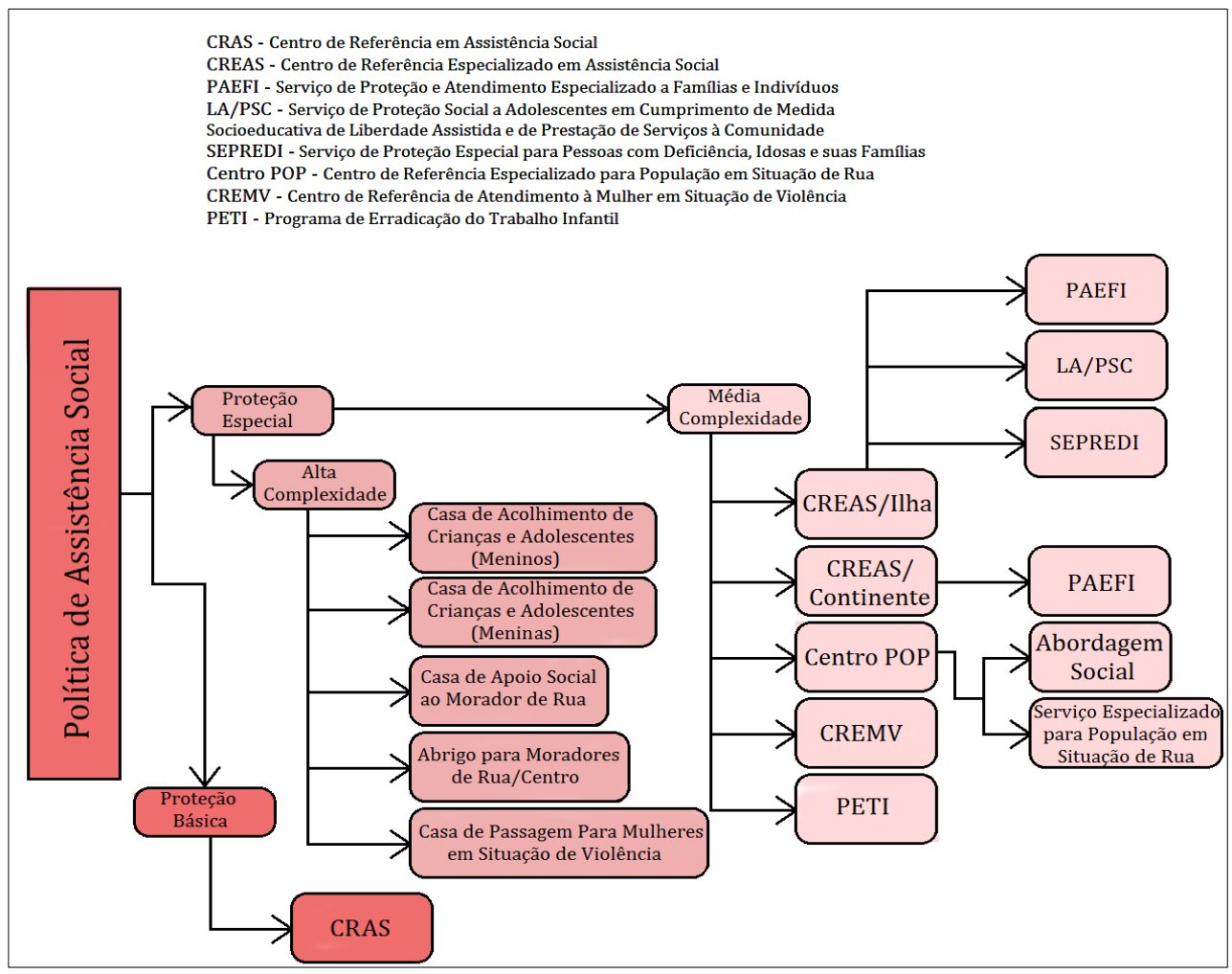

Fonte: Lima e Botega (2016).

O Serviço de Proteção e Atendimento a Famílias e Indivíduos (PAEFI) é recente no Sistema Único de Assistência Social. O PAEFI, aprovado em 11 de novembro de 2009, pela Resolução no 109 , atende crianças, adolescentes e suas respectivas famílias em situação de direitos violados. Deve-se ressaltar que se entende por direitos violados:

Violência física, psicológica e negligência; Violência sexual: abuso e/ou exploração sexual; Afastamento do convívio familiar devido à aplicação de medida socioeducativa ou medida de proteção; Tráfico de pessoas; Situação de rua e mendicância; Abandono; Vivência de trabalho infantil; Discriminação em decorrência da orientação sexual e/ou raça/etnia; Outras formas de violação de direitos decorrentes de discriminações/submissões a situações que provocam danos e agravos a sua condição de vida e os impedem de usufruir autonomia e bemestar; Descumprimento de condicionalidades do PBF e do PETI em decorrência de violação de direitos. (BRASIL, 2012, p. 18).

Dessa forma, o Serviço de Proteção e Atendimento a Famílias e Indivíduos adentra no Sistema de Garantia de Direitos, sendo categorizado como Serviço de Assistência Social de Média Complexidade. Os atendimentos aos(às) usuários(as) do PAEFI ocorrem a partir de uma perspectiva psicossocial e objetivam restaurar e fortalecer os vínculos 
familiares e sociais, auxiliando os indivíduos e suas famílias para que haja rompimento e enfrentamentos das violências e subsidiando os indivíduos envolvidos para que a reincidência não ocorra. Para isso, o trabalho ocorre juntamente com os(as) profissionais que compõem a rede de proteção e atenção às crianças e aos adolescentes: conselhos tutelares, judiciário, saúde, educação, habitação etc.

\section{Método}

Esta pesquisa caracteriza-se como análise documental por tratar de documentos cientificamente autênticos (PÁDUA, 1997). Tal delineamento se viabiliza pela busca de conteúdos escritos em fontes diversas nas quais exigem dos(as) pesquisadores(as) um processo de garimpagem e manuseio ético neste processo, ainda mais quando se trata de documentos de domínio público, visto que:

Os documentos públicos são produtos sociais tornados públicos. Eticamente estão abertos para análise por pertencerem ao espaço público, por terem sido tornados públicos de uma forma que permite responsabilização. Podem refletir as transformações lentas em posições e posturas institucionais assumidas pelos aparelhos simbólicos que permeiam o dia a dia [...]. (SPINK, 2000, p. 136).

Diante ao fato de nossa pesquisa ter como objetivo analisar documentos de domínio público, para realização deste trabalho foram seguidos todos os preceitos éticos em pesquisa. Primeiramente, obtivemos a autorização pela gestão da secretaria municipal de assistência social e, em seguida, o projeto foi enviado e aprovado pelo Comitê de Ética em Pesquisa da Universidade Federal de Santa Catarina ${ }^{7}$.

Como instrumento de coleta de dados, foram acessadas as estatísticas produzidas pelos(as) profissionais do Serviço PAEFI/Ilha no primeiro semestre de 2016. O acesso aos dados foram realizados semanalmente por duas estagiárias do curso de Pedagogia da UFSC ${ }^{8}$. Porém, antes de adentrarmos ao campo, realizamos um estudo amplo e detalhado sobre a política de assistência social e do instrumento quantitativo que era utilizado no serviço nomeado pelos(as) técnicos(as) de "Estatística". Todo este trabalho foi supervisionado pela professora coordenadora do projeto e por uma psicóloga do PAEFI/Ilha integrante do projeto9. Destacamos que a "estatística" era enviada a coordenação do serviço pelos(as) técnicos(as) no início de cada mês e que os dados eram armazenados e, posteriormente, enviados para a gestão municipal a fim de alimentar os dados sobre a política pública.

Ao longo do percurso, descobrimos que o instrumento quantitativo utilizado em 2016 foi modificado no ano de 2015 por um grupo de profissionais
7 Número de aprovação do projeto no Comitê de Ética: CAAE: 81638817800000121.

$8 \mathrm{Na}$ época, uma das estagiárias era Pamela Cristina dos Santos, uma das autoras deste texto.

9 A profissional a que nos referimos é Gisely Pereira Botega, uma das autoras deste texto. 
$10 \mathrm{O}$ MDS foi extinto quando o atual (des)governo assumiu no início de 2019. Com isso, o SUAS passou a estar vinculado ao Ministério da Cidadania. do PAEFI/Ilha que percebeu a necessidade de aprimorar o instrumento quantitativo anteriormente utilizado. $\mathrm{O}$ instrumento anterior era um modelo repassado aos serviços pelo antigo Ministério de Desenvolvimento Social e Combate à Fome $(\mathrm{MDS})^{10}$ e não continha algumas informações, entre elas, um campo de identificação no qual pudesse ser registrado o quesito raça/cor dos(as) usuários(as). Portanto, trata-se de um instrumento que foi (re)construído para pensar tal contexto e todas as singularidades que ele abarca. Além disso, tal iniciativa revela o interesse e compromisso destes(as) profissionais em problematizar suas práticas e seus saberes.

As estagiárias acessaram os dados no espaço físico do PAEFI em dias e horários previamente definidos. Os dados estatísticos foram disponibilizados para serem acessados nos computadores do referido serviço. Ademais, contou-se com o apoio da coordenação, especialmente de uma assistente administrativa que era responsável pela compilação e organização em planilhas dos dados enviados pelos(as) técnicas mensalmente. Destacamos que os dados aos quais tivemos acesso não continham o registro dos(as) nomes dos(as) profissionais nem das famílias e dos indivíduos/usuários(as) da política. Isso garante, assim, o sigilo ético. Em seguida, faremos a análise dos dados a partir do que Spink e Frezza (2000) chamaram de práticas discursivas, ou seja, práticas que demonstram os diversos modos a partir dos quais os sujeitos produzem sentidos e se posicionam em relações sociais cotidianas.

A categoria raça/cor e as estatísticas do serviço paefi: reflexões possíveis acerca do branqueamento da política de assistência social

Para a análise da categoria raça/cor, mapeamos dados referentes aos 299 casos atendidos pelo PAEFI no segundo semestre do ano de 2016. Vale salientarmos que o número de casos é contabilizado pelo número de famílias; então, considerando que uma família é constituída por duas ou mais pessoas, o número de pessoas atendidas pelo programa é muito mais elevado. Desse modo, destacamos que de janeiro a julho de 2016 o Serviço PAEFI atendeu cerca de 651 pessoas. Para compor a nossa discussão, apresentamos a seguir o terceiro gráfico, o qual nos dá uma breve visualização de raça/cor dos(as) usuários(as) do serviço. E, apesar de prevalecer a cor parda, há uma grande percentagem de "não informado". Tais dados sugerem uma invisibilidade da raça/cor na estatística de Florianópolis. 


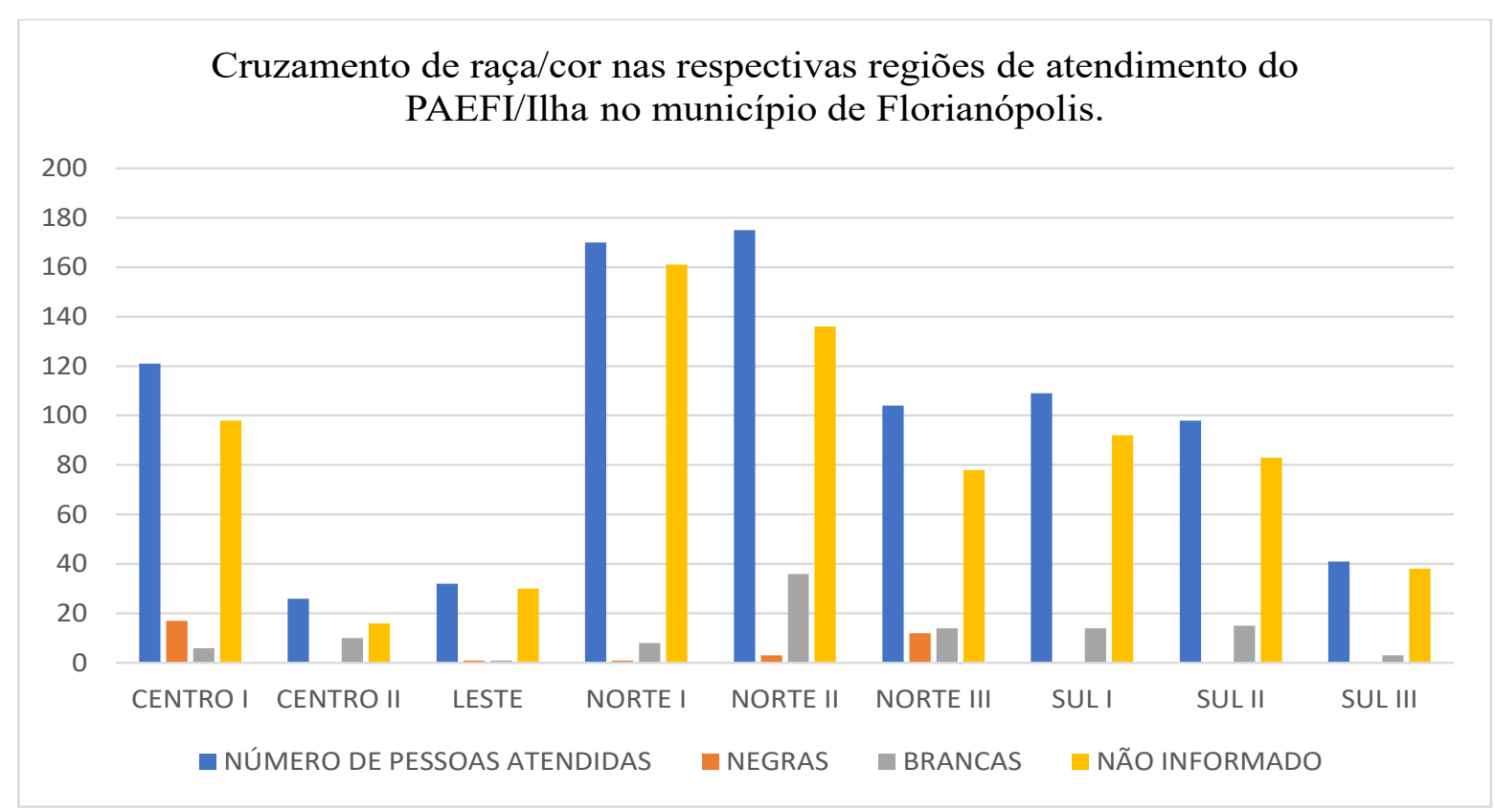

Gráfico 1: Cruzamento de raça/cor nas respectivas regiões de atendimento do PAEFI/Ilha no município de Florianópolis, referente aos atendimentos realizados de Janeiro a Julho de 2016.

Fonte: Estatística semestral do PAEFI/Ilha, 2016.

A partir da análise inicial do Gráfico 1, notificamos que grandes partes dos registros de raça/cor aparecem como "não informados". Para compreendermos esta lacuna de preenchimento, faz-se necessário acionar as discussões acerca da classificação e identificação racial no Brasil. Destacamos que o conceito de raça nasceu atrelado a uma perspectiva biológica de hierarquização racial e que somente a partir do século XVIII passou a ser encarado por uma perspectiva sociológica. Isso significa que o uso atual do conceito raça tem sido adotado politicamente para evidenciar as desigualdades sociais e raciais que atingem as populações afetadas pela construção histórica e biológica do referido conceito (MUNANGA, 2003). Vale destacarmos que a construção racial no Brasil possui um padrão etnocêntrico em que a constituição do outro se dá pela distância dos sujeitos deste padrão; ainda, devido ao processo de miscigenação, possuímos uma diversidade racial que permite que a construção da raça seja relacional. Com isso, queremos afirmar que um sujeito pode transitar entre as categorias de classificação racial a depender do local do país em que se encontra.

Segundo Osório (2003, p. 7), “[...] a classificação racial é entendida como o conjunto de categorias em que os sujeitos da classificação podem ser enquadrados"; assim, o sistema classificatório atual pode ser realizado por autoatribuição ou heteroatribuição. Reconhecemos a autoatribuição como 
um mecanismo político de identificação racial das populações; ao mesmo tempo, evidenciamos o padrão de brancura como uma herança colonial que paira sobre o imaginário social que exerce movimentos de negativar as identidades negras. Tal fator não só contribui para que ocorram movimentos de ascensão social para atingir um padrão de brancura hegemônico como também permite levantar hipóteses acerca do alto índice das não declarações raciais apresentadas nos gráficos apresentados anteriormente.

Atrelado a isso, necessitamos localizar que esses dados sobre identificação racial correspondem à região sul do Brasil, local em que o processo de colonização teve como um de seus objetivos o povoamento; tão logo, existiu grande processo de imigrantes europeus. Conforme Leite (1996), Santa Catarina é um estado povoado por uma imensa diversidade racial, onde habitam descendentes de italianos, poloneses, alemães, açorianos, africanos etc., mas sempre passou uma imagem de "estado branco"; mais do que isso, de uma Europa incrustada no Brasil, de superioridade racial, de desenvolvimento e progresso.

E esse dado influencia na composição do racial da população no estado de Santa Catarina que apresenta pouco mais de $17 \%$ da sua população autodeclarada preta ou parda, um dos menores índices dos estados brasileiros. Ainda, quando acionamos as autodeclarações para a cidade de Florianópolis, este número se aproxima de 15\%, segundo os dados do instituto Brasileiro de Geografia e Estatística (IBGE, 2010). Desse modo, quando trazemos os dados apresentados no Gráfico 1, tais informações necessitam serem consideradas.

Nesse sentido, sinalizamos que a classificação racial no Brasil está diretamente ligada às marcações fenotípicas dos sujeitos, tal como dizem pesquisadores(as) como Azevedo (1951), Ianni (1998), Munanga (2008), Guimarães (1999) e tantos(as) outros(as). Com isso os modos com que as classificações raciais são mais complexas do que definir quem é branco(a) e quem é negro(a), no sentido de que dentro de uma mesma família pode existir uma variação considerável, como mostram os estudos de Schucman (2014).

Assim, a classificação racial utilizada pelo Serviço PAEFI segue a versão utilizada pelo IBGE (preto, pardo, branco, indígena e amarelo), ainda, estas são realizadas por heteroatribuição. Considerando o exposto até o momento e a lógica de racionalidade hegemônica, a heteroatribuição no contexto de uma cidade no sul do Brasil tende a acompanhar o movimento de branqueamento da população.

Assim, quando o Gráfico 1 representa o baixo aparecimento da população negra no atendimento aos serviços do PAEFI, necessitamos adentrar nas especificações destes, pois são conflituosos.

Tal fato nos permite inferir sobre os processos de branqueamento tangenciados por um processo histórico e social que perpassa as relações 
sociais e o acesso aos sistemas de direitos. Torna-se crucial destacar que a não marcação da raca/cor nos bancos de dados das políticas públicas, aqui com destaque para o PAEFI, interfere diretamente na consolidação dos direitos e na formulação de políticas e ações outras destinadas à população negra. Desse modo, tensionar acerca da racionalidade hegemônica implica reaver os movimentos da branquitude presentes no preenchimento da marcação racial pelos(as) técnicos(as) das políticas públicas. Ao sinalizar isto, não é nossa intenção culpabilizar os(as) profissionais uma vez que estamos incidindo sobre um elemento de ordem estrutural, mas pontuamos e tensionamos tais aspectos a partir do entendimento do compromisso social coletivo. Assim, tal elemento não isenta os(as) profissionais da responsabilidade social diante de tais questões que devem cotidianamente ser questionadas e tensionadas já que estão diretamente ligadas à constituição e consolidação de direitos sociais.

Dito isso, não podemos deixar de citar os estudos de Barbosa (2007) que analisa 74 prontuários de casos que foram desligados no ano de 2006 no antigo Programa Sentinela de Florianópolis, a partir da categoria raça/cor e de como, mediante esta informação, os(as) profissionais (psicólogos(as) e assistentes sociais) produzem intervenções nos casos que envolvem crianças e adolescentes negros(as) imersos(a)s em contextos de violências. A autora apresentou algumas narrativas de psicólogos(as) e assistentes sociais e, a maioria, mostrou desconhecimento sobre a questão racial e, ao mesmo tempo, uma noção de que a informação racial não era um dado que possuía sentidos e significados às práticas de atenção para com as crianças e os adolescentes. Com relação raça/cor nos prontuários, mostrou que em grande parte não havia o registro deste quesito.

A pesquisa de Barbosa (2007) nos auxilia na sustentação dos nossos argumentos, pois expressa movimentos de branqueamento dos sujeitos a quem se destina a política pública, mesmo que se refira à política anterior. Ainda, nos permite atualizar e até comparar informações passadas mais de uma década, já que os dados dessa autora foram coletados em 2006 e os nossos em 2016. O que observamos neste percurso não é nada animador, pois encontramos invisibilidade em relação ao quesito cor/raça nas estatísticas produzidas pelo trabalho de psicólogos(as) e assistentes sociais. A defesa de práticas institucionais que focalizassem apenas a violência e, não a raça, pode sugerir:

Que a violência denunciada está "descolada" das múltiplas experiências dos sujeitos em relação às práticas outras de violência, mais sutis e não menos dolorosas e destrutivas como no caso do racismo. Desconsidera-se a relação do fenômeno da violência com as diversas hierarquias sociais entre os sujeitos, e, portanto, torna mais vulneráveis uns que outros. (BARBOSA, 2007, p. 43). 
11 Sinalizamos que compreendemos a perspectiva pela qual o conceito de violência tem sido utilizado pelo PAEF/ILHA, mas que nossos diálogos acerca deste conceito pode ser mais bem explicitada por Santos (2004) e Arendt (2009).
Além disso, Barbosa (2007) nos ajuda a problematizar sobre as formas de silenciamentos da violência racial enfrentadas pelas crianças e pelos adolescentes negros(as), aos(às) quais incluímos as famílias negras. Tais silenciamentos são produzidos nas famílias, nas escolas e, em espaços de atendimentos aos sujeitos que são vítimas de violências. Mas, se nos espaços de atendimentos suas experiências de desqualificação e violência racial não forem reconhecidas, onde serão? Portanto: "Há que provocar análises mais refletidas sobre esta questão, junto às políticas de atendimento e de combate às violências contra a criança e adolescente" (BARBOSA, 2007, p. 83).

No que tange às violências que atingem crianças e adolescentes, o Serviço PAEF/ILHA conta com dois procedimentos de registro distintos: I. Violências relatadas no ato da denúncia e II. Violências identificadas pelo PAEF/ILHA. O uso desses dois modos de registro se deve ao fato de que, no ato da denúncia, pode ser registrada apenas uma violência sofrida por um sujeito (criança/adolescente); contudo, na medida em que o Serviço PAEF/ILHA atende aos sujeitos, estes podem também ser vítimas de outras violências não registradas na denúncia. Desse modo, um registro tende a complementar o outro. Vale ressaltar que o PAEF/ILHA compreende as violências ${ }^{11}$ por uma perspectiva jurídica, em que estas são a expressão do direito do sujeito - seja este uma criança e/ou um adolescente - que foi violado. Logo, interessa ao serviço o reestabelecimento da condição de cidadão ou cidadã que outrora tenha sido infringido por outrem.

Assim, ao explorarmos um mapeamento das violências que atingiram crianças e adolescentes pela perspectiva racial, temos: 


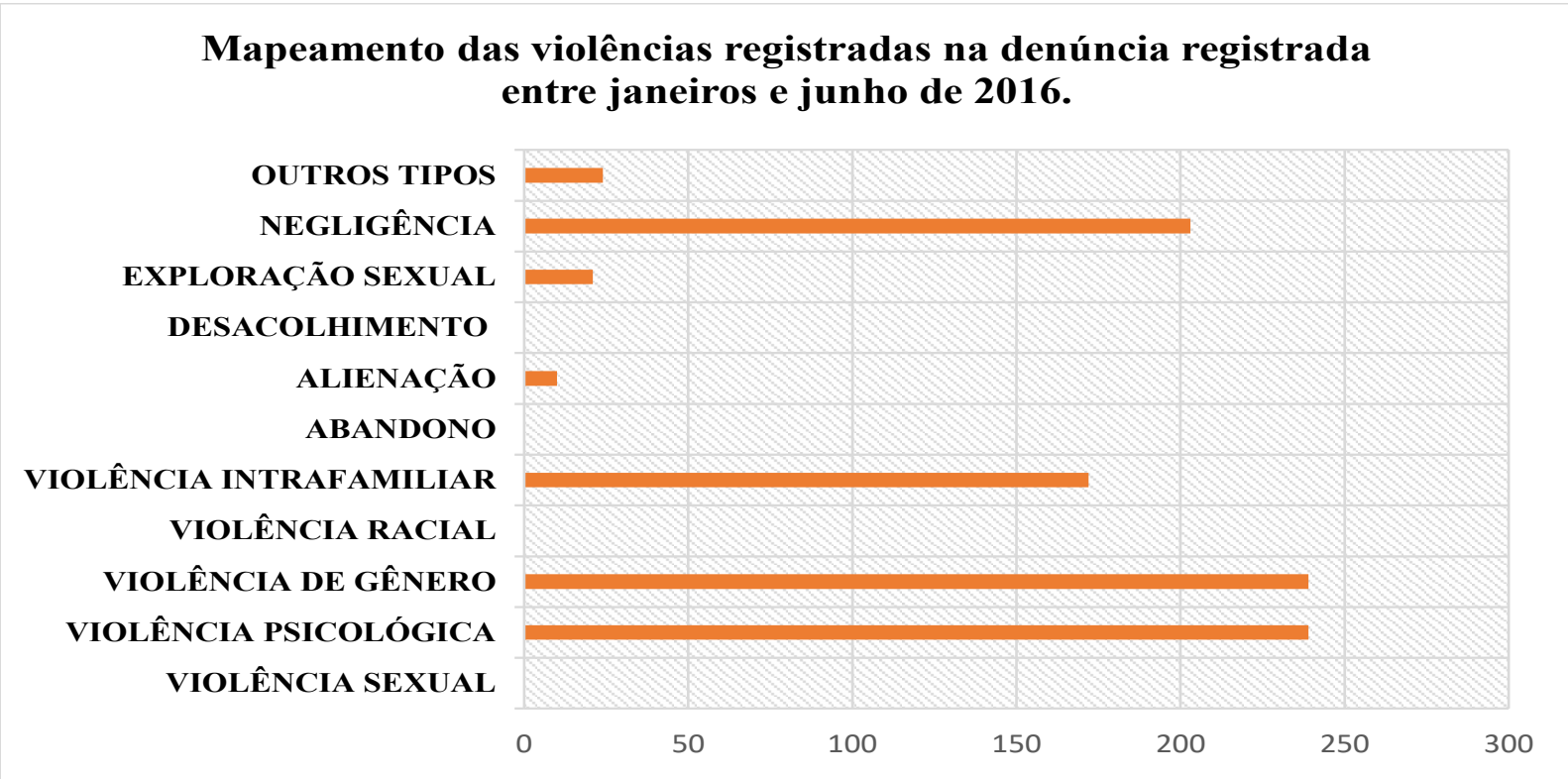

Gráfico 2: Mapeamento das violências registradas nas denúncias registradas entre janeiro e julho de 2016 antes do atendimento.

Fonte: Estatística semestral do PAEFI/Ilha, 2016.

Mapeamento das violências identificadas pelo Serviço PAEF/ILHA após o atendimento entre janeiros e junho de 2016

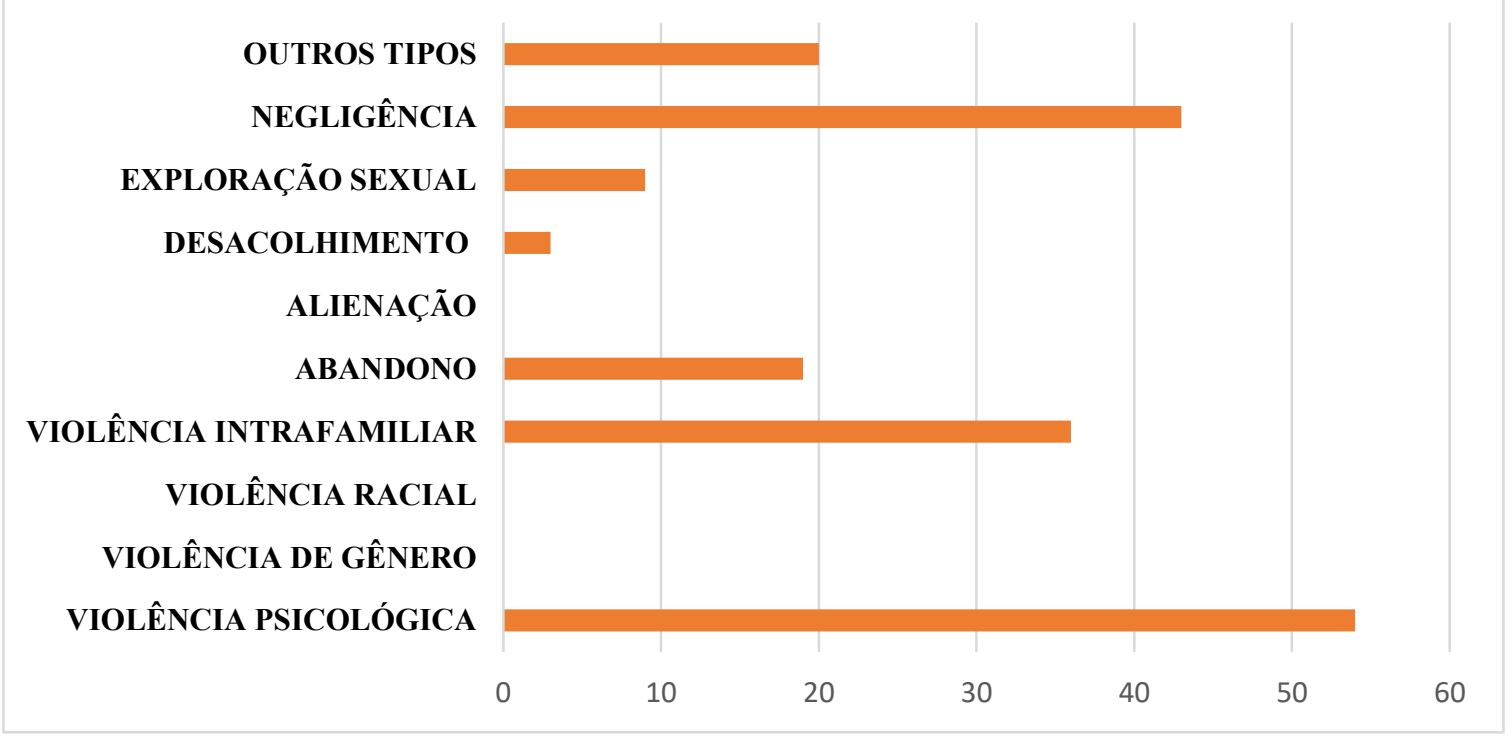

Gráfico 3: Mapeamento das violências identificadas pelo Serviço PAEF/ILHA entre janeiros e junho de 2016 após o atendimento. 
Os dados apresentados no Gráfico 2 e no Gráfico 3 são referentes aos mesmos casos. Porém, no primeiro, temos a expressão da denúncia que chegou ao PAEF/ILHA; no segundo, o registro feito pelos(as) profissionais após o atendimento. Vejamos que há uma série de variações acerca das violências, com destaque para a violência física, violência psicológica e para a negligência. Ainda, após a realização do olhar qualificado dos(as) profissionais, existe uma redução considerável do que pode ser considerado violência através da perspectiva da violação do direito. Contudo, para apurar a redução dos motivos que levam a tais reduções frente ao número expressivo comparado as denúncias, seriam exigidos momentos mais alargados de pesquisa, o que não dispomos nesse momento; por esse motivo, sinalizamos nossa percepção acerca destes, da mesma forma que abrimos possibilidades outras de exploração dos dados.

Seguindo com nossa perspectiva, chamamos a atenção de que no Gráfico 2 existe o registro de denúncia de violência racial; contudo, após a realização do atendimento, esta violência foi suprimida dos dados. Através da análise dos gráficos, é possível apenas levantar hipóteses acerca da supressão deste registro após o atendimento do PAEF/ILHA. Da mesma forma, considerando os resultados da pesquisa de Barbosa (2007) como também os registros de notificação da não identificação da raça/cor nos formulários analisados, podemos inferir possibilidades de olhares que não reconhecem o fator racial como um quesito fundante da constituição e da violação de direitos.

Considerando a raça como estruturante das relações e desigualdades sociais no Brasil (PASSOS, 2012), o não reconhecimento da raça/cor como possibilidade latente de violência corrobora diretamente para a violação dos direitos da população negra e para a manutenção das desigualdades sociais e raciais na sociedade brasileira. Junto a isso, com base na estatísticas, é "[...] um instrumento sociopolítico, ativo, utilizado no trabalho desenvolvido pelas mesmas, à medida que sistematiza e articula informações de aspectos quantitativos e qualitativos" (BARBOSA, 2007, p. 38). Tão logo, ao evidenciarmos tais percepções através da análise de dados, principalmente no cenário político em que vivenciamos um conjunto expressivo das diversas humanidades em risco, lançamos mão de perguntas para reflexões insurgentes, tais como: quais compromissos sociais têm sido acordados para com a população negra para a efetivação dos direitos e a diminuição das desigualdades sociais?; Se pela produção das estatísticas os sujeitos não são marcados pela raça/cor, quem são as crianças e os adolescentes atravessados(as) pela Política de Assistência Social?; Quais perspectivas de direitos violados/violências estão imbricadas na formação dos(as) profissionais para o atendimento dessas crianças e adolescentes para o reestabelecimento do direito? 


\section{Algumas considerações}

Tendo como pano de fundo o objetivo deste artigo, apresentamos dados do serviço PAEF/ILHA a partir de gráficos produzidos pela estatística de psicólogos(as) e assistentes sociais referentes aos atendimentos do ano de 2016. As análises deste trabalho são provisórias e não pretendem gerar generalizações. Vale destacar que os dados aqui analisados e mapeados nos trazem muito mais perguntas do que respostas, na medida em que abrem brechas para a discussão da violência racial em um serviço de atendimento a crianças, adolescentes e suas famílias. Vale ressaltar, que os(as) referidos(as) profissionais não foram ouvidos(as) nem mesmo os usuários(as) do serviço, questão que pode ser incluída em futuras pesquisas.

Os resultados apontam para uma invisibilidade na estatística da categoria raça/cor tanto em relação à identificação dos(as) usuários(as) como nas violências identificadas pelo serviço. Acreditamos que seja fundamental esta discussão no serviço para análises e atualizações da política de assistência social. Podemos inferir aspectos latentes acerca do branqueamento da população negra da cidade de Florianópolis através da notificação existente nos dados referentes à declaração racial dos(as) usuários(as) do serviço PAEF/ILHA, consideramos a não marcação racial como um elemento que colabora para acentuar as desigualdades sociais e raciais existentes no Brasil. Por fim, destacamos a importância de olharmos para as crianças e os adolescentes e suas respectivas famílias através do recorte racial, principalmente no sul do país. Assim, a raça/ cor é um elemento fundamental para atingirmos a consolidação e/ou reestabelecimento dos direitos, uma vez que - considerando os aspectos sociais, políticos e históricos sob os quais vivemos - não é possível que famílias negras sejam vistas do mesmo modo que famílias brancas frente aos direitos sociais.

\section{Referências}

ALENCAR, Sandra Regina Serafim Ayres de. Condições Institucionais E Exercicio Profissional-Desafios Postos Para O Serviço Social Na Efetivação Do Programa Sentinela No Município De Florianópolis. Orintador: Edaléa Maria Ribeiro. 74 f. Trabalho de Conclusão de Curso (Bacharelado em Serviço Social) - Departamento de Serviço Social, Universidade Federal de Santa Catarina, Florianópolis, 2007.

ARENDT, H. [1906-1975]. Sobre a Violência. Tradução de André de Macedo Duarte. Rio de Janeiro: Civilização brasileira, 2009.

AZEVEDO, C. M.M. Onda negra, medo branco: o negro no imaginário das elites - século XIX. Rio de Janeiro: Paz e Terra, 1951.

BARBOSA, R. A questão do quesito raça/cor nos prontuários do Programa 
Sentinela. Orientadora: Ana Maria Borges de Souza. 2007. 85 f. Dissertação (Mestrado em Educação) - Programa de Pós-Graduação em Educação, Universidade Federal de Santa Catarina, Florianópolis, 2007.

BRASIL. Lei no 8.069, de 13 de julho 1990. Dispõe sobre o Estatuto da Criança e do Adolescente e dá outras providências. Disponível em http://www.planalto.gov. br/ccivil_03/leis/18069.htm. Acesso em: 26 dez. 2017.

BRASIL, Conselho Nacional de Assistência Social. Brasília: dezembro de 2012.

BRASIL. Tipificação Nacional de Serviços Socioassistenciais. Brasília: Ministério do Desenvolvimento Social e Combate à Fome, 2009.

GIL, A. C. Como elaborar projetos de pesquisa. 4. ed. São Paulo: Atlas, 2002.

Google Maps. LOCALIZAÇÃO CREAS/ILHA. 2019. ?. Disponível em: https://www.google.com.br/maps/place/CREAS+Ilha+-+Centro+de+Referência +Especializado+de+Assistência+Social/@-27.6361376,-48.7189548,12z/data=!4 m8!1m2!2m1!1spaefi+ilha!3m4!1s0x9527387259baaa75:0x895fb2b28c065bf2!8 m2!3d-27.5740184!4d-48.5360744. Acesso em: 26 dez. 2017.

Governo do Estado de São Paulo. Secretaria De Desenvolvimento Social. São Paulo, 2016. Disponível em: http://www.desenvolvimentosocial.sp.gov.br/portal. php/assistencia_sistema. Acesso em: 26/08/2019.

Guimarães, A. S. A. Racismo e anti-racismo no Brasil. São Paulo: Fundação de apoio à Universidade de São Paulo; Editora 34, 1999.

IANNI, O. As Metamorfoses do Escravo: apogeu e crise da escravatura no Brasil Meridional. São Paulo: Hucitec, 1988.

Instituto Brasileiro de Geografia e Estatística (IBGE). Censo Demográfico 2010. Disponível em: https://ww2.ibge.gov.br/home/estatistica/populacao/censo2010/ default.shtm. Acesso em: 26 dez. 2017.

ZAPELINI, C. A. E. (Org.). Módulo 2: violências, Rede de Proteção e Sistema de Garantia de Direitos. Florianópolis: NUVIC-CED- UFSC-2010.

LEITE, I. B. Descendentes de Africanos em Santa Catarina: invisibilidade histórica e segregação. In: LEITE, I. B. (Org.). Negros no sul do Brasil. Florianópolis: Contemporâneas, 1996. p. 33-53.

LIMA, F. C.; SCHNEIDER, D. R. Característica da atuação profissional do psicólogo na Proteção Especial em Santa Catarina. Revista Psicologia: Ciência e Profissão, v. 38, n. 2, p. 347-362, 2018.

LIMA, P. de M. Infância(s), Alteridade e Norma: dimensões para pensar a pesquisa com crianças em contextos não institucionais. Revista Currículo sem fronteiras, v. 15, n. 1, p. 94-106, 2015.

LIMA, P. de M. Rede de Proteção, Defesa e Controle dos Direitos: mapeamento do risco e da vulnerabilidade na infância em Florianópolis. Projeto de Extensão CED/UFSC. Florianópolis: UFSC, 2016.

LIMA, P. de M.; SANTOS, P. C.; BOTEGA, G. P. Risco e vulnerabilidade: desafios na rede de proteção à infância no município de Florianópolis. Revista zero a seis, v. 18, n. 34, p. 288-302, jul./dez. 2016. 
MUNANGA, K. Uma Abordagem Conceitual Das Noções De Raca, Racismo, Identidade E Etnia. Palestra proferida no $3^{\circ}$ Seminário Nacional Relações Raciais e Educação-PENESB-RJ, 05/11/03.

Rediscutindo a mestiçagem no Brasil : identidade nacional versus identidade negra. Belo Horizonte, MG: Autêntica Editora, 2008

OSORIO, Rafael Guerreiro . O sistema de classificação de cor ou raça do IBGE. Brasília: IPEA, 2003 (Texto para Discussão).

PÁDUA, E. M. M. de. Metodologia da pesquisa: abordagem teórico prática.2. ed. Campinas: Papiros, 1997.

PASSOS, J. C. As desigualdades na escolarização da população negra e a educação de jovens e adultos. EJA em debate, v. 1, p. 137-150, 2012.

PEGASO, C. Programa de Excelência na Gestão da Assistência Social. Florianópolis: Federação Catarinense de Municípios (FECAN), [s. d.].

FLORIANÓPOLIS. Projeto Técnico de Referência Sentinela. Florianópolis: Secretaria da Criança, Adolescente, Idoso, Família e Desenvolvimento Social, 2005

Schucman, L. V. Entre o encardido, o branco e o branquíssimo: branquitude, hierarquia e poder na cidade de São Paulo. São Paulo: Annablume, 2014.

SILVA, F. de M. S. O Perfil do Denunciante do Projeto SOS Criança do Município de Florianópolis: Uma Análise da Denúncia como Instrumento de Cidadania. Orientador: Carolina Hoeller da Silva. 2004. 74 f. Trabalho de Conclusão de Curso (Bacharelado em Serviço Social) - Departamento de Serviço Social, Universidade Federal de Santa Catarina, Florianópolis, 2004.

SOUSA, A. M. B. O sentido institucional de acolher: por uma Gestão do Cuidado com as crianças violentadas. In: SOUSA, A.M. B.; Vieira, A.; Lima, P. de M.(Org.). Ética e gestão do cuidado: a infância em contextos de violências. Florianópolis: CED/UFSC, 2006. p. 21-46.

SOUSA, A. M. B. Violências: o que se esconde por entre as sinuosidades do detalhe. In: SOUZA, A. M. B.; BARBOSA, I. B. Cuidar da Educação, cuidar da vida. Florianópolis: UFSC, 2011. p. 9-27.

SOUSA, A. M. B. Infância e Violência. O que a escola tem a ver com isso? Orientador: Malvina do Amaral Dorneles. 2002. 210 f. Tese (Doutorado em Educação) - Programa de Pós-Graduação em Educação, Universidade Federal do Rio Grande do Sul, Porto Alegre, 2002.

SOUZA, A. M. B.; LIMA, P. de M.; MIGUEL, D. A gestão do cuidado e educação biocêntrica. Florianópolis: UFSC-CED-Nuvic, 2010.

SPINK, P. Análise de documentos de domínio público. In: SPINK, M. J. Práticas discursivas e produção de sentidos no cotidiano: aproximações teóricas e metodológicas. 2. ed. São Paulo: Cortez, 2000. p.100-127.

SPINK, M. J.; FREZZA, M. R. Práticas discursivas e produção de sentidos: a perspectiva da Psicologia Social. In: SPINK, M.J. Práticas discursivas e produção de sentidos no cotidiano: aproximações teóricas e metodológicas. 2. ed. São Paulo: Cortez, 2000. p.1-22. 
ZAPELINI, C.A. E. (Org.). Módulo 2: violências, Rede de Proteção e Sistema de Garantia de Direitos. Florianópolis: NUVIC-CED- UFSC-2010.

Recebido: $19 / 03 / 2019$

Aceito: 08/05/2019. 


\title{
THE PROTOCOL OF SPECIALIZED ATTENDANCE SERVICETO FLORIANOPOLIS FAMILIES: A RACIAL SURVEYEL
}

\begin{abstract}
This article aims to reflect on the production of statistical data regarding race/color, of the year 2016, carried out by psychologists and social workers of a Specialized Family and Individual Care and Protection Service (PAEFI) located within the Center for Reference of Social Assistance (CREAS) located in Greater Florianópolis. Like this we to liste the race/color markings through statistics produced monthly by professionals of this service, which prioritize a psychosocial work approach to the violated rights of children, adolescents and their families. The results point to an absence of this quantitative mark in the statistics suggesting a process of invisibility to the racial issues that can produce violence in different contexts.
\end{abstract}

Keywords: Race/color. Service PAEFI. Racial violence. Childrens and adolescents.

\section{SERVICIO DE PROTECCIÓN Y ATENCIÓN ESPECIALIZADO A FAMILIAS DE FLORIANÓPOLIS: UN LEVANTAMIENTO RACIAL}

\begin{abstract}
Resumen
Este artículo tiene como objetivo reflexionar sobre la producción de datos estadísticos referentes al tema raza/color, del año 2016, realizados por psicólogos y asistentes sociales de un servicio de Protección y Atención Especializada a Familias e Individuos (PAEFI) situado dentro del Centro de Referencia de Asistencia Social (CREAS) ubicado en la Grande Florianópolis. Se asignan las marcas de raza/color a través de estadísticas producidas mensualmente por los profesionales de este servicio, los cuales priorizan un abordaje de trabajo psicosocial frente a los derechos violados de niños, adolescentes y sus familias. Los resultados apuntan a una ausencia de esta marcación cuantitativa en las estadísticas sugiriendo un proceso de invisibilidad ante las cuestiones raciales que pueden producir violencias en diferentes contextos.
\end{abstract}

Palabras clave: Raza/color. Servicio PAEFI. Violencia racial. Niños y adolescentes. 